\title{
Signaling effects and the role of culture: Movies in international auxiliary channels
}

\begin{abstract}
Given the high uncertainty in the quality perception of experiential products, manufacturers use signals to influence consumers' decisions. In the movie industry, literature shows that performance of the main channel (e.g., cinema) strongly influences the performance of auxiliary channels (e.g., DVDs). The success of a movie in the home country is also to be resonated by its good performance in host countries. However, the cultural contingency of these success-breeds-success (SBS) effects has not been examined. Our research tests the influence of cultural values on the SBS effects across channels and countries. Borrowing concepts from the signaling literature and analyzing DVD sales data from six international markets using a multilevel mixed-effect model, we find that culture plays significant roles to influence both SBS effects. In countries with high power distance high long-term orientation and low indulgence consumers who purchase from auxiliary channels are less likely to be influenced by the box office performance of movies. Meanwhile, cultural distance between the home and host nations significantly decreases the cross-national SBS effect. This paper contributes to the existing literature by investigating the international auxiliary channels of movies and incorporating cultural values into the framework of sequential distributions. This study is the first one to test the links between the main and auxiliary channels from an international marketing perspective. Our research suggests that the SBS effects may vary across nations. When managers plan for the sequential distributions of experiential products, the cultural values of target markets should be considered to decrease the uncertainty in sales prediction.
\end{abstract}

Keywords: Cultural values, auxiliary channels, international markets, movies, hierarchical mixed-effect models. 


\section{Signaling effects and the role of culture: Movies in international auxiliary channels}

\section{Introduction}

Sequential distribution is the process by which products are made more accessible to consumers via their releases in different markets and channels sequentially (Lehmann and Weinberg 2000). Overseas markets and auxiliary channels are supposed to prolong the product life cycle and provide a greater revenue basis for the same new product line for an extended period of time (Calzada and Valletti, 2012, Hennig-Thurau et al., 2006). The movie industry has widely adopted the strategy of sequential distribution (Elberse and Eliashberg, 2003, Eliashberg et al., 2006), and research results have confirmed the benefits of such a strategy (Bruce et al., 2012, Hennig-Thurau et al., 2006, Chintagunta et al., 2010, HennigThurau et al., 2007, Lehmann and Weinberg, 2000). Given that the theatrical revenue in the US accounts for only $13 \%$ of the total cost of movie production, and more than $70 \%$ of box office revenue comes from international markets (MPAA, 2017, MPAA, 2011), the US market explains only a fraction of the total revenue of the movie industry. A second type of sequential distribution is auxiliary channels. For instance, consumers in the US spent $\$ 18$ billion on videos for home entertainment in 2015, with DVD purchases and rentals contributing 34\%, while online subscription and video-on-demand (VOD) contributed the rest 66\% (The Convergence Consulting Group, 2016). These numbers and results from academic research point to the relevance of sequential distribution and the fact that an understanding of these revenues is vital to the movie industry (Eliashberg et al., 2006).

Consumers rely on signals to infer the quality of movies before purchase (Basuroy et al., 2006, Dhar et al., 2012, Moon et al., 2010). According to the signaling theory, the success of movies in the home market and the primary channel should be used by consumers as signals in both international markets and auxiliary channels. This is termed as the success- 
breeds-success (SBS) effect. Although the SBS effects have been found in both crossnational (e.g., Elberse and Eliashberg, 2003, Neelamegham and Chintagunta, 1999) and cross-channel (e.g., Lehmann and Weinberg, 2000, Luan and Sudhir, 2010, Ahmed and Sinha, 2016) sequential distributions, previous studies have not investigated both simultaneously. Connecting these two perspectives of sequential distribution is important, because the existence and strength of signaling effects may differ across nations. In some countries, box office revenues and auxiliary sales are closely correlated, while in others, box office performance is not echoed by the response from auxiliary channels. Sometimes the success of movies transcends national borders, but in other cases, the good performance of movies in the home country is not resonated in host nations. Therefore, in this paper, we set to explain the divergence in the SBS effects across borders and channels by introducing the cultural variables, providing a new perspective to understand sequential distributions. The movie industry would be one of the best product category and a fertile ground for understanding the influence of culture on the SBS effects because of its cultural relevance, international presence and multi-channel distribution system.

Table 1 summarizes previous studies investigating sequential distributions of movies. Our study focuses on a void of research — international auxiliary channel—and tries to address three important but yet-to-be resolved questions: (1) Whether the SBS phenomenon exists in international auxiliary channels for experiential products like movies? (2) Does national-level culture moderate the SBS effects? (3) Does the moderation effect still exist when endogeneity, such as time interval from movie release is controlled for? Our study extends the extant literature in three directions. First, we model the different factors that affect the revenues of auxiliary channels in both domestic and international markets. Second, although previous studies have highlighted the importance of signals in the overall success of products in international markets (Elberse and Eliashberg, 2003, Weinberg, 2005, Weinberg, 
2006, Erdem et al., 2006), the role culture in cross-channel and cross-national distribution still needs investigation. To the best of our knowledge, this study is the first to test the effects of cultural variables on the demand for auxiliary channel products in international markets while controlling for movie-specific and timing factors. Lastly, our study combines Hofstede's cultural framework with the literature on movies to develop and test a novel theoretical framework that provides insight into the role that cultural variables play in shaping consumer behavior in this category.

Table 1 about here

To examine these issues, we first provide a detailed description of the conceptual framework with a review of the related literature and the model development, followed by data description, results and discussion, a conclusion, and some directions for future research.

\section{Sequential distributions of the movie industry}

In a sequential distribution system, the channel through which the product is released initially is defined as the main channel (e.g., box office for movies), whereas the auxiliary channel (e.g., DVDs, video on demand, and online subscription) is the one through which a variant of the product is released after a time lag. Due to increased competition, the time interval between main and auxiliary channels has been shortened, which makes the difference between main and auxiliary channels depend less on the time of product release (Eliashberg et al., 2006). However, industry norms would still consider theatrical releases as main channels. To delay the emergence of pirated products in the markets, theatrical releases generally precede releases in auxiliary channels (Smith and Telang, 2009b). Among all auxiliary channels, the motion picture DVD market is the most typical one in terms of 
revenues and influence (Weinberg and Moul, 2005). Therefore, to investigate the interplay between main and auxiliary channels in international markets, movies and DVDs provide a good research context. Our findings can be generalized to other auxiliary channels, such as online streaming market, and other entertainment industries, such as concerts, as well.

\section{Success-breeds-success (SBS) effects}

Signaling theory is the central pillar for explaining consumers' quality perception of experiential products. Consistent with Raghunathan and Corfman (2006), we describe movies, and by extension, DVDs, as examples of experiential products that are diffused and sold in different nations and channels. Quality of movies cannot be fully assessed before consumption, so signals are used to inform quality judgment (Carrillat et al., 2018, Hofmann et al., 2017). Recent studies have shown that the worldwide revenue of the movie industry is still growing, but the number of products being released in North America market is also increasing from 2001 to 2017 . Consumers are facing more choices in the selection of movie products than before. In addition to the monetary cost of movies, time cost of consumption should also be considered. Therefore, consumers have the impetus to infer the quality of movies, through a learning process, before making decisions, because watching an unfavorable movie can be rather costly. This learning process hinges on the use of product signals. Quality indicators such as studios, genres, directors, star power, sequels, remakes, and production spending have been tested to influence quality perception of movies (Akdeniz and Talay, 2013, De Vany and Walls, 1999, Karniouchina, 2011). Recently, with the advent of the Internet and social media, movie buzz becomes a vital source of signals (Liu, 2006, Divakaran et al., 2017, Hennig-Thurau et al., 2015). Consumers rely on expert critics, users' review, and social media to acquire product information. For purchases from auxiliary channel and international markets, another type of signal, the success of the movie in the 
home country and the main channel, is relevant as well. Due to intervals between releases, the box office performance of the home country becomes an important overall signal for international markets and auxiliary channels.

From a managerial perspective, to predict the performance of products in international auxiliary channels, two diffusion processes are identified: the diffusion of new products from home to host countries, and the diffusion from main to auxiliary channels. Most companies, including born global ones such as Airbnb, adopt a waterfall strategy for international expansion, whereby products are released first in the home country and then distributed globally. Previous literature on international diffusion of innovations clearly demonstrates the cross-border SBS effect (Hennig-Thurau et al., 2006, Kogut and Singh, 1988, Johnson and Tellis, 2008). Researchers believe that adopters in lag markets learn from customers in lead markets (Ganesh and Kumar, 1996, Ganesh et al., 1997), indicating a learning procedure across national borders (Duan et al., 2008, Chintagunta et al., 2010). Based on this finding, managers select the successful products in home market to be introduced to host countries. On the other hand, the success of main channels can also be carried forward to the outcomes of auxiliary channels. For example, consumers of motion picture DVDs can obtain valuable information from the success of the same movie in the theatrical channel (Ahmed and Sinha, 2016, Luan and Sudhir, 2010). Following this logic, we assume that the success of movies, both in the home and host countries' primary channels, will affect the product's success in the host country's auxiliary channels.

From a consumer perspective, the theoretical foundations of the SBS effects can be explained from three aspects. First, the SBS effects are consistent with the brand signaling theory, in which information about a product is carried by branding, as an all-in-one and diagnostic signal to influence consumers' decision making under different buying circumstances. If each movie is viewed as a distinctive brand, then its brand equity, obtained 
from its previous success, can be extended to new markets and channels (Erdem et al., 2006, Erdem et al., 2004, Roth, 1995). As Erdem and Swait (1998) explain, brand equity increases quality perception, decreases the risk of making the wrong purchase decision, and decreases the information searching cost, and a combination of these three aspects eventually increases consumer utility. In a similar vein, a movie's success in the theatrical channel or in the home country increases the perceived quality and decreases the possibility of consuming undesired products. Second, the SBS effects can be explained by the buzz of movies. The success or failure of movies in the theatrical channel or in the home country generates buzz or word-ofmouth through multiple media outlets (Duan et al., 2008, Hennig-Thurau et al., 2015, Neelamegham and Jain, 1999). The buzz forms an important information cue for potential consumers, influencing the quality perception of movies (Liu, 2006, Divakaran et al., 2017, Karniouchina, 2011). According to Elberse and Eliashberg (2003), moviegoers "jump on the bandwagon" of popular movies, and media outlets give disproportional attention to popular movies as well, with positive information of the movie cascading across time and space. The empowerment of social media accentuates the SBS effects by enhancing the relevance of movie buzz as a type of cross-country signals (Chung, 2011). Movie buzz can be an instrumental mechanism that mediates the SBS effects. Third, the SBS effects can be explained by the power of social influence. The nature of social influence is complex. Researchers of social psychology provided a categorization of social influence based on dimensions such as majority vs. minority, public vs. private, congruence vs. noncongruence, initial agreement vs. disagreement, etc. (Nail, 1986, Moscovici, 1980, Kelman, 1958). In the movie industry, consumers are influenced by at least two types of social opinions: information and norm-based influence (Deutsch and Gerard, 1955). For information-based influence, consumers' attitudes towards the movie are either reinforced or converted due to the diagnostic information provided by individuals or a minority group. Consumers make 
more informed and accurate decisions due to the help of others (Broekhuizen et al., 2011). For norm-based influence, consumers are influenced by the public opinions towards the movie, which are usually reflected by its buzz in media and its overall popularity. Here, consumers conform to the opinion of the majority without thinking divergently and independently (Childers and Rao, 1992). Both types of social influence will be boosted by the initial success of a movie in the primary channel or the home country, fueling the SBS effects in sequential distributions. These three theories do not contradict each other, but jointly constitute the theoretical foundation for the SBS effects. Therefore, we believe that:

H1: There is a positive success-breeds-success effect across borders, where the homecountry sales performance influences the host-country sales performance for movie products.

H2: There is a positive success-breeds-success effect across channels, where the sales performance in the main channel influences sales performance in the auxiliary channels for movie products.

The cross-national and cross-channel SBS effects are well supported by the literature, but previous studies have also indicated that the SBS effects might not be identical in magnitude across countries (Ganesh and Kumar, 1996). Consumers' relative reliance on the SBS signals can differ, and this difference can be caused by values that are deeply rooted in one's cultural values (Ladhari et al., 2011). In the literature, there has been a collection of evidences to suggest that culture may impact the level we submit to social influence (Bond and Smith, 1996, Money et al., 1998), which motivated us to explore deeper into the contingency of the SBS effects. More specifically, we want to find out whether the sizes of SBS effects show significant deviation depending on markets, and whether the differences in SBS effects can be explained by cultural values. 
Figure 1 about here

\section{The role of national culture}

We explain the international difference in the SBS effects by incorporating dimensions of cultural values proposed by Hofstede (1980). Hofstede's paradigm, subject to criticisms, is not the only approach to capture the complex nature of culture, but it is still the most enthusiastically used tools in international marketing research (Soares et al., 2007). Researchers argue that the cultural values can be studied at an individual level (Ogden and Cheng, 2011), but national-level culture is also valid due to clustering effects (Minkov and Hofstede, 2011). We decided to investigate the influence of individualism, uncertainty avoidance, power distance, long-term orientation, and indulgence at a national level to examine their impact on the SBS effects and offer managerial implications accordingly. The cultural values were chosen because of their theoretical relevance to the SBS effects. Before we starting the discussion, it should be clarified that culture can be operationalized in many other ways (Shavitt et al., 2006, Schwartz and Bilsky, 1990), and our approach to understand the differences in the SBS effects is by no means the only plausible explanation. Therefore, this investigation serves just as the first cut into the research of international auxiliary channels, waiting for more insights from other facets of cultural or national differences.

A country's culture has long been identified as an environmental characteristic that influences consumers' adoption of innovations. Consumers from different countries show systematic differences in innovativeness (Steenkamp et al., 1999) and new product adoption (Van Everdingen and Waarts, 2003). Previous studies investigated the impact of culture on the customer adoption of high-tech and utilitarian products. Van den Bulte and Stremesch (2004), for instance, show that uncertainty avoidance, individualism, and power distance 
affect the speed of diffusion. Other researchers, such as Van Everdingen and Waarts (2003), find a significant influence from all of Hofstede's cultural dimensions on the adoption rate of the Enterprise Resource Planning (ERP) system in European nations. Tellis et al. (2003) find that the adoption rates of 10 consumer durables (e.g., washing machines, freezers, VCRs, etc.) are faster in countries with low uncertainty avoidance scores than in countries high with uncertainty avoidance. Yaveroglu and Donthu (2002) also uncover a significant connection between Hofstede's cultural dimensions and the adoption rates of consumer durables. These studies have not investigated the impact of culture on the SBS effects of experiential products. The interaction between nations and channels in the diffusion process is also unattended. The SBS learning process, enabled by powerful new media, becomes increasingly important in purchase decisions of international experiential products. Borrowing arguments from the signaling literature, movie buzz and research on social influence, we contend that culture is influencing and will continue to influence the performance of international auxiliary channels as a powerful moderator on both crosschannel and cross-national sequential distributions. National level culture increases (or decreases) the SBS effects by influencing consumers' reliance on brand signals, their reaction to buzz, and their assimilation of social influences.

\section{The moderating role of cultural values on cross-channel sequential distribution}

Individualism vs. collectivism and uncertainty avoidance. Individualism captures the degree to which people in a country prefer to act as individuals rather than as members of groups. Uncertainty avoidance measures how much the society is threatened by uncertain situations and the extent to which these situations are to be avoided. Uncertainty avoidance should increase the need for brand signaling, but individualism should decrease it (Erdem et al., 2006, Tifferet and Herstein, 2010, Roth, 1995). Erdem et al. (2006) suggest that brand 
credibility's overall impact in a nation will be increased by uncertainty avoidance and decreased by individualism, because uncertainty avoidance increases the need for accuracy in information searching, and consumers in a high-uncertainty avoidance culture are more likely to collect and examine brand information before making purchase decisions. Their empirical studies in seven countries on FMCGs and durables confirmed these arguments. Akdeniz and Talay (2013) also argue that collectivism and uncertainty avoidance increase the reliance on, and importance of, signals of movies, including sequel, budget, star power, and reviews. For movies and DVDs, the uncertainty of consumption mainly comes from not being able to experience the expected fun and pleasure after watching the movie. The information from the main channel can inform consumers' decisions in auxiliary channels. Consumers in uncertainty avoidance cultures should value these signals more because the chance of consuming undesired experiential products is reduced. From a perspective of social influence, researchers have investigated the role of cultural dimensions on conformity and compliance (Bond and Smith, 1996, Hofstede, 1980), informational influence (Ng and Van Dyne, 2001, Pornpitakpan and Francis, 2000), and social influence in general (George et al., 2012, Erdem et al., 2006). A commonly accepted conclusion is that collectivists are more likely to be motivated by norms imposed by the ingroup, and therefore conform to group pressures (Mourali et al., 2005). The informational influence is stronger in collectivist society: studies have shown that ties between friends and reference groups are stronger in such society, and stronger interpersonal ties can reinforce the power of interpersonal referrals (Money et al., 1998). Uncertainty avoidance society is also influenced more by expert opinions (Pornpitakpan and Francis, 2000), which is also part of the cross-channel SBS effect. Therefore, we predict that the performance of auxiliary channels should be more informed by the revenues of the main channel where uncertainty avoidance and collectivism are high. 


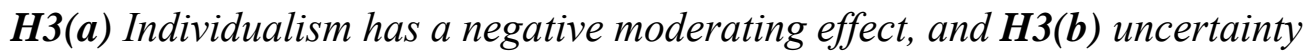
avoidance has a positive moderating effect on the success-breed-success effects from the main channel to auxiliary channels for movie products.

Power distance. Unlike individualism and uncertainty avoidance, the moderating effects of power distance on brand reliance are yet to be decided and tested. This paper extends the research effort of Erdem et al. $(1998,2006)$ by exploring the impact of power distance on the SBS effect across channels. Power distance is defined as the degree to which less powerful consumers accept the disparity or inequality of power in a society (Hofstede et al., 2010). The acceptance of one's rightful place in a social hierarchy is crucial in the definition of power distance. Roth (1995) argues that power distance belief increases conformity from consumers to their actual or aspired social classes, because they are motivated to behave similarly as their ingroup members. In other words, if consumers connect social status or class differences with brands they consume, they are more likely to embrace brands with a social image that fits their own or ideal identity, especially in public circumstances where social images of brands become relevant. Similarly, Wang et al. (2018) find that consumers with high power distance belief are more likely to categorize brands into social groups. They develop more brand trust and better assessment towards ingroup brands than outgroup ones. From these studies, we know that the acceptance of ingroup brand signals can be boosted by power distance, but power distance can also decrease the diagnosticity of signals when they are associated with outgroups, because different social classes in a high power distance society are less trusting of each other (Dawar and Parker, 1994, Hofstede, 1980, Dawar et al., 1996). Power distance should make consumers distrust the brands that do not fit their own social class in terms of brand image and associations. Moreover, although power distance per se does not measure the level of power disparity or 
inequality, a more hierarchical structure, in which consumers' personal tastes and preferences for hedonic consumption diversify greatly, usually characterizes a high power distance society (Donthu and Yoo, 1998). The distrust in outgroups, together with a difference in preference structures and expectations in high power distance society, makes consumers less likely to convert their product preferences in private when power distance is high.

From the perspective of social influence, previous literature provides inconclusive answers to the influence of power distance. In this study, we adopt Festinger and Carlsmith (1959)'s categorization of internalization and compliance to disentangle the opposite moderating effects of power distance. Power distance has been tested to accentuate the social value of brands where awareness of hierarchy and identity is involved (Erdem et al., 2006, Roth, 1995, Kim and Zhang, 2011). Therefore, power distance can increase the salience of social influence and brand signals when public compliance is involved. Consumers adopt certain brands in pursuit of prestigious social status rather than accurate perception of product quality (Wang et al., 2018). However, when internalization is required to make purchase decisions, power distance may decrease the relevance of social influence. For example, Erdem et al. (2006) contend that consumers in high power distance society are featured with strong distrust against the authority in private circumstances. Consumers in low power distance cultures are more likely to be active opinion seekers of impersonal information, and their online research into brands is also stronger (Goodrich and de Mooij, 2014). For DVD consumption, internalization is important than compliance in decision making, because external pressure of consumption is barely strong, and a true internal preference of products leads to purchases. Therefore, we expect that power distance would decrease consumers' reliance on box office success when they buy from auxiliary channels.

H3(c) Power distance has a negative moderating effect on the success-breed-success effects from the main channel to auxiliary channels for movie products. 
Long-term orientation. The SBS effects can be both short- and long-term, but due to its nature as momentary buzz, the largest wave of impact of the SBS effects happens right after product releases rather than in the distant future. The dimension of long-term orientation measures a pragmatic preference of future values over historic or short-term values (Hofstede et al., 2010). In the literature, long-term orientation is suggested to slow down the diffusion of innovations (Donthu and Yoo, 1998, Dwyer et al., 2005). Similarly, long-term-oriented consumers tend to evaluate brands over longer periods of time and become less influenced by short-term trends (Eisingerich and Rubera, 2010). Their emphasis on perseverance, thrift, and deferred satisfaction also mitigates the impact of a sudden emergence of brand signals or new information. Long-term-oriented cultures do not pursue truth eagerly, and their frugal use of resources limits their immediate acceptance or adoption of a new product (Donthu and Yoo, 1998). In their mind, no opinions, including buzz of movies, can be absolutely right, and time provides the best screen for new ideas and products. In contrast, Hofstede et al. (2010) describes short-term-oriented countries as showing stronger sensitivity to social trends in consumption, which means brand signals from the SBS effects can place stronger influence on them.

From a social influence perspective, researchers propose that long-term orientation decreases the influence of word-of-mouth on service expectations, regardless of its valence (Nath et al., 2018). Goodrich and de Mooij (2014) find empirical evidences to suggest that long-term-oriented consumers have less trust of recommendations from family and friends on social media when making purchase decisions. We can generalize these findings to infer that long-term orientation may dilute the persuasive power of short-term social influence, because short-term social influence may not maintain the same intensity into the future. The SBS effects of movies, as explained earlier, have been tested to hold greater social influence 
shortly after the release date, but their long-term influence on information receivers should follow a declining curve (Chung, 2011). Therefore:

H3(d) Long-term orientation has a negative moderating effect on the success-breedsuccess effects from the main channel to auxiliary channels for movie products.

Indulgence vs. restraint. The cultural value of indulgence is a relatively new dimension in Hofstede's system, which is defined as a tendency to allow gratifications of desires that are related to fun and pleasure, whereas restraint is "a conviction that such gratification needs to be curbed and regulated by strict social norms" (Hofstede et al., 2010, p. 281). Because movies are hedonic products that aim to bring satisfaction and pleasure ${ }^{1}$, indulgence should positively influence movie consumption in all channels. The influence of indulgence on the SBS effects, on the other hand, is hinged on the sensitivity to signals. Akdeniz and Talay (2013) test the interaction of indulgence and movie signals such as sequel and star power, and they find a positive moderation effect. Consumers who have a higher tendency to indulge in movies should also keep more active communication of this hedonic consumption with others. Therefore, their sensitivity to social trends of the industry is higher than those in restraint cultures. Consumers in countries with higher restraints demonstrate need-based purchase behavior and do not accept new ideas readily (Lu et al., 2018). Their adoption of movie buzz would be less active.

In addition, the indulgence literature suggests that consumers expect more positive affect for their future indulgent activities, when there is a reason for indulgence $\mathrm{Xu}$ and Schwarz, 2009). This is because when the episodic details of indulgence are not available, consumers turn to the general knowledge of the indulgence for information. Good theatrical

\footnotetext{
${ }^{1}$ Movies can also trigger discrete negative emotions during the consumption process, but these negative emotions are part of the overall satisfaction at the end of movie watching. Different theories (e.g., stress and relief theory, sensory delight, etc.,) have explained why consumers spend money and time to experience negative emotions from movies.
} 
performance of movies provides a solid justification for indulging a very similar DVD product. Therefore, to indulge better, consumers have the motivation to actively search for positive signals of movies before buying from auxiliary channels. In restraint cultures, gratifications are not encouraged, and consumers lack the motivation to enhance the future values of indulgent activities. A reduced sensitivity to the SBS effects is more likely to be found in restraint nations. Therefore:

H3(e) Indulgence has a positive moderating effect on the success-breed-success effects from the main channel to auxiliary channels for movie products.

\section{The moderating role of culture on cross-national sequential distribution}

Although movies from other countries are shown in the US, the dominant pattern is for US movies to be sequentially released and shown in other countries (Craig et al., 2005). Researchers widely acknowledge the global impact of American movies (Elberse and Eliashberg, 2003, Akdeniz and Talay, 2013), but this impact can vary by countries. We believe that culture, specifically cultural distance, moderates the impact of a movie's success in the home country on its performance in auxiliary channels of international markets.

Previous research has shown that cultural distance, measured by the Euclidean distance of the four Hofstede cultural dimensions between the host and home countries, affects the rate of product adoption in the host country: the greater the distance, the slower the diffusion process (Johnson and Tellis, 2008, Mitra and Golder, 2002). Consumers with similar cultural values tend to have similar beliefs, customs, and lifestyles, and they favor culturally congruent entertainment. More specifically, Ganesh et al. (1997) hypothesize and test the idea that cultural similarity has a positive influence on the learning effects between lead and lag markets because "learning occurs more frequently between individuals who are alike, or homophilous" (p. 217). Putsis et al. (1997) consider the learning between lead and 
lag markets to be a result of "mixing," which the authors define as the interaction of market segments. Cultural proximity facilitates mixing behavior between nations, and consequently boosts consumer learning across national borders. Craig et al. (2005) find that when they control for language differences between nations, cultural distance still shows a strong negative influence on the adoption of American movies in host countries. Although the optimal distinctiveness theory suggests that consumers sometimes search for uniqueness rather than assimilation in products to reflect one's multiple social identity (Brewer, 2003), such desire for uniqueness can be satisfied by available select criteria of movies such as genre and starring (Chan et al., 2012). More importantly, culture influences the value perceptions of products and daily routines of consumers (Soares et al., 2007), so closer cultural distance facilitates the interpersonal bonding and trust between consumers from different nations (Wan et al., 2012). Therefore, close distance increases the chance that marketing signals in the home country being followed and trusted by the consumers in host nations. In general, consumers in nations that are culturally close to the US are predicted to trust the recommendations from US more than those in culturally distant nations. The success of movies in the US is more likely to be replicated in host nations that have similar cultural values. Therefore, we hypothesized that cultural distance would negatively moderate the cross-national SBS effect:

H4 Cultural distances between the home and the host countries have a negative moderating effect on the relationship between the performance of the main channel in the home country and auxiliary channels in host countries.

\section{Data and model specification}

Data used to calibrate the model are of DVD markets from six different countries: Australia, Japan, Germany, the United Kingdom, the United States, and France. For each of 
the countries, the IPSOS group provided data pertaining to the sales of motion picture DVDs in the year 2005 with information of distributors, product features such as special edition and sequel, and the time intervals between theatrical and DVD releases. Table 2 provides a summary of the sources of all variables in this research. The data comprise a total of 104 Hollywood movies, a subset of which was released through the main and auxiliary channels in the six international markets. Table 3 provides descriptive statistics for motion picture DVDs included in the sample.

Table 2 and Table 3 about here

Figure 2 illustrated the main and auxiliary channel performance of movies in six nations. The US had better performance in both channels due to the large market size. UK and Australia showed stronger cross-channel SBS effects like US. The slopes are less steep in Germany, France and Japan. Figure 3 illustrated the SBS effects across borders. Box office performance in the US provided signals for auxiliary purchases in the other five countries. The slopes in UK and Australia were steeper than the rest.

\section{Figure 2 and Figure 3 about here}

We used a multilevel mixed-effects $\log -\log$ model to test the hypotheses. The model development was similar to the earlier work by Neelamegham and Chintagunta (1999), Elberse and Eliashberg (2003), and Luan and Sudhir (2010). We modeled the cumulative DVD sales for $4,8,12$, and 26 weeks, keeping in line with the industry, which tends to make distribution and marketing decisions for DVD within these time windows. This was analogous to using a movie's first-week revenues to make or tweak subsequent marketing 
and distribution decisions. Consistent with prior research (Luan and Sudhir, 2010), we assumed that the logarithm of cumulative unit sales $\left(D V D_{i j t}^{\text {host }}\right)$ for DVD $i$ in country $j$ in a time window $t$ was a function of the product's success in the home-country market as well as in host-country markets:

$$
\begin{aligned}
& \ln \left(\text { DVD }_{i j t}^{\text {host }}\right)=\beta_{0 i j}+\beta_{1 i j} \times \ln \left(\text { Boxoffice }_{i j t}^{\text {host }}\right)+\beta_{2 i j} \times \ln \left(\text { Boxoffice }_{i j t}^{\text {home }}\right)+\beta_{3} \times \text { Edition }_{i j}+\beta_{4} \times \ln \left(\text { Price }_{i j}\right)+ \\
& \beta_{5} \times \ln \left(\text { Interval }_{i j t}^{\text {movie }}\right)+\beta_{6} \times \ln \left(\text { Interval }_{i j t}^{\text {DVD }}\right)+\beta_{7} \times \ln \left(\text { Star }_{i}\right)+\beta_{8} \times \text { Sequel }_{i}+\beta_{9} \times \text { Remake }_{i}+ \\
& \sum_{k} \beta_{10 \mathrm{k}} \times \text { Yahoo }_{i k}+\beta_{11} \times \ln \left(\text { UserRating }_{i}\right)+\beta_{12} \times \ln \left(\text { MovieMeter }_{i}\right)+\beta_{13} \times \ln \left(\text { Duration }_{i}\right)+\beta_{14} \times \\
& \ln \left(\text { Streaming }_{i}\right)+\beta_{15} \times \ln \left(\text { Torrents }_{i}\right)+\beta_{16} \times \ln \left(\text { Seeds }_{i}\right)+\beta_{17} \times \ln \left(\text { Leeches }_{i}\right)+\sum_{m} \beta_{18 m} \times \text { Rating }_{i m}+ \\
& \sum_{l} \beta_{19 l} \times \text { Genre }_{i l}+\beta_{20} \times \ln \left(\text { Device }_{j}\right)+\beta_{20} \times \ln \left(\text { Distributors }_{j}\right)+\varepsilon_{i j t} \\
& \beta_{0 i j}=\gamma_{00}+\gamma_{01} \times \ln \left(C V_{I D V j}\right)+\gamma_{02} \times \ln \left(C V_{U A I j}\right)+\gamma_{03} \times \ln \left(C V_{P D I j}\right)+\gamma_{04} \times \ln \left(C V_{L T O j}\right)+\gamma_{05} \times \ln \left(C V_{I D G j}\right)+\mu_{0 i j} \\
& \beta_{1 i j}=\gamma_{10}+\gamma_{11} \times \ln \left(C V_{I D V j}\right)+\gamma_{12} \times \ln \left(C V_{U A I j}\right)+\gamma_{13} \times \ln \left(C V_{P D I j}\right)+\gamma_{14} \times \ln \left(C V_{L T O j}\right)+\gamma_{15} \times \ln \left(C V_{I D G j}\right)+\mu_{1 i j} \\
& \beta_{2 i j}=\gamma_{20}+\gamma_{21} \times \ln \left(C D_{j j \prime}\right)+\mu_{2 i j}
\end{aligned}
$$

In Equation (1), Boxoffice ${ }_{i j t}^{\text {host }}$ and Boxoffice ${ }_{i j t}^{\text {home }}$ were the total box office revenues in the international and the US market. To test the moderating effects of culture, its direct impact should be controlled as demonstrated in Equation (2). In Equation (3), $\beta_{1 i j}$ was the coefficient measuring the effect of host-country box office revenue on DVD sales. The coefficient $\gamma_{10}$ represented the direct effect of host-country box office sales on the success of motion picture DVDs, whereas the coefficients $\gamma_{11}, \gamma_{12}, \gamma_{13}, \gamma_{14}$ and $\gamma_{15}$ provided estimates for the moderating effects of the cultural values. In Equations (4), consistent with Johnson and Tellis (2008), we calculated the cultural distance between a home country $j$ ' and a host country $j$ as the Euclidean distance among all five Hofstede dimensions of culture included in this study. The coefficients $\gamma_{21}$ estimated the moderating effects on the cross-national SBS effect, which should be negative according to the hypothesis.

Table 4 about here 
We chose control variables following the suggestion of Bernerth and Aguinis (2016). Factors that may impact the performance of sequential distributions were incorporated into the model. We included three levels (DVD, movie, and country levels) of control variables. For the DVD level, we included information on whether the DVD was of a special edition and its original price. Previous studies propose that time intervals between DVD releases in host countries and other revenue windows are crucial factors to predict the performance of auxiliary channels (Hennig-Thurau et al., 2006, Duan et al., 2008), so these intervals were incorporated into our analysis. Normally, time intervals between box office and DVD releases have negative influence on DVD sales, but in some cases, intervals facilitated auxiliary channel performance (Ahmed and Sinha, 2016). Because our focus was the impact of culture rather than intervals between releases, we treat both time intervals as control variables. The time intervals since host movie and DVD releases were measured.

For movie level variables, we included genres, content ratings, star power, sequel, remake, critics' review, user ratings, and duration of movies because of their relevance in predicting movie performance. The content ratings had four categories: G, PG, PG-13, and R.

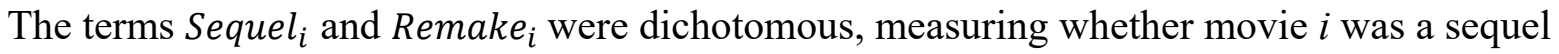
or a remake. Star $i$ measured the star power of the movie. Yahoo Movie $\left(\right.$ Yahoo $\left._{i k}\right)$ reviews reflected the experts' opinions of the movies, and a categorical score was given to each movie. Internet Movie Database (IMDb) ratings (UserRating $)_{i}$ represented the peer evaluation of movies. Online video-on-demand services formed a different auxiliary channel to compete against the DVD market. We measured the popularity of online streaming services by aggregating the total number of customer ratings for each movie on Amazon Prime and Vudu platforms. These two international platforms provided online access to a particular movie, which could be used to control for competition effect at the movie level. Piracy was an important factor influencing auxiliary channels. According to the literature (De 
Vany and Walls, 2007, Smith and Telang, 2009a), piracy data could be collected by calculating the total number of seeds and leeches of active torrents. Numbers of active torrents from three major torrent search engines (SumoTorrent, SkyTorrents, and LimeTorrents) were counted. Each torrent had a variety of seeds and leeches, which were also aggregated across three search engines to form indicators of pirate activities.

At a national level, the penetration of DVD playing devices and DVD distribution networks were important. Two types of DVD playing devices existed in 2005: stand-alone players and DVD drivers on computers and laptops. We adopted the higher ownership percentage of the two as an indication of technological diffusion. The density of DVD distribution networks was measured by the total number of DVD distributors in a nation as documented in the data.

A complicating factor was that time intervals between releases were endogenous to the system, implying that treating them as exogenous variables would lead to estimation bias. For example, managers might deliberately delay the release of DVD because the box office performance was still healthy and stable. But to maximize the total revenues from the main and auxiliary channels, managers might shorten the intervals for highly anticipated movies (Ahmed and Sinha, 2016). To minimize endogeneity while controlling for effects of intervals, an approach was to use studios as instruments (Luan and Sudhir, 2010). Consistent with Park and Gupta (2009), we controlled for the effects of endogeneity by correlating the two random terms $\mu_{0 i j}$ and $\xi_{i j}$ from Equation (1) and Equation (5) and estimated their covariance $\vartheta$.

$$
\ln \left(\text { Interval }_{i j}^{\text {Movie }}\right)=\alpha^{\text {lag }}+\sum_{s}\left(\theta_{i s} \times \ln \left(\text { studio }_{i s}\right)\right)+\xi_{i j}
$$

\section{Model estimation and data analysis}

We calibrated a multilevel (DVD and movie levels) mixed-effects models that allowed us to test the different hypotheses using Proc Mixed in SAS with restricted maximum 
likelihood estimators. The analysis was conducted in two phases, and each cultural influence on the SBS effects was tested separately to avoid multicollinearity, which was a common approach when a few cultural dimensions and their moderations need to be tested (Akdeniz and Talay, 2013, Lu et al., 2018). In Phase I, the influence of all control variables were tested simultaneously at two levels, with instruments of studios also included. The covariance of errors between Equation (1) and (5) was significant $(\vartheta=.150, \mathrm{p}<.001)$. The coefficients for the time intervals showed a downward adjustment when endogeneity was controlled. The residual of the model was used as the dependent variable for a Phase II analysis to examine the SBS effects and moderation effects of culture as indicated in Equation (2), (3), and (4).

Phase II treated all cultural variables as fixed effects. We adopted mean-centering on box office revenues and cultural values to alleviate the multicollinearity of interaction terms. A separate OLS estimation based on the same analysis approach showed that all VIF values were less than ten. All models that included cultural values added significant explanatory power to the residual of Phase I analysis, indicating that SBS effects and cultural moderations were important predictors for performance in international auxiliary channels.

\section{Table 5 about here}

Table 5 provided the estimations of coefficients. The cross-channel SBS effects were examined on each cultural dimension, and all of them are significant. The cross-national SBS effect $\left(\gamma_{20}=.153, \mathrm{p}=.006\right)$ was significant as well. Therefore, $\mathrm{H} 1$ and $\mathrm{H} 2$ were supported. The results showed that the moderating effects of three cultural dimensions, power distance $\left(\gamma_{13}=\right.$ $-.449, \mathrm{p}=.044)$, long-term orientation $\left(\gamma_{14}=-.857, \mathrm{p}=.003\right)$, and indulgence $\left(\gamma_{15}=.659\right.$, $\mathrm{p}=.001$ ), were in expected directions, implying that countries that have higher scores for power distance and long-term orientation and lower scores for indulgence tend to give 
relatively less attention to the box office success of a movie when purchasing a DVD. These results supported $\mathrm{H} 3(\mathrm{c}), \mathrm{H} 3(\mathrm{~d})$, and $\mathrm{H} 3(\mathrm{e})$. However, the moderation effects of individualism and uncertainty avoidance were not significant, indicating a lack of empirical support for H3(a) and H3(b). Cultural distance between two countries moderates the cross-national SBS effect $\left(\gamma_{21}=-.121, \mathrm{p}<.001\right)$, implying that the greater the cultural distance between the home and host country, the lesser the effect of home-country box office on DVD sales in host nations. We found support for $\mathrm{H} 4$.

The effects of control variables were examined. First, time intervals since DVD releases had positive influence on DVD sales $\left(\beta_{6}=.146, \mathrm{p}<.001\right)$, which was natural as we used accumulative sales as dependent. Star power influenced DVD sales at a marginally significant level. As expected, user ratings had a significant impact on DVD sales. Piracy was positively related to DVD sales, so the competing effect was not uncovered. This was because download of movies can be viewed as an illegal auxiliary channel, and the two auxiliary channels were both influenced by SBS effects from the main and international markets and become spuriously correlated. Table 5 did not show the results for critics from Yahoo movies, because there were eight different grades, and none of these grades had significant influence on DVD sales. Of the different genres used as control variables, animation was the only one sold significantly better than horror movies. There was a strong correlation between the penetrate rate of DVD devices and the number of distributors. When both were included as predictors, distribution networks had a significant influence on DVD sales whereas availability of DVD devices was not significant.

\section{Discussions}

This paper identified factors that influence the performance of international auxiliary channels. Four out of five hypotheses were supported, so we could infer that the effects of 
culture on sequential distributions existed. Culture moderated the SBS effects across geographic regions and channels. Consumers in nations with high power distance, long-term orientation, and low indulgence were less likely to be influenced by box office success when consumers purchased from auxiliary channels such as motion picture DVDs. Lastly, we confirmed that the greater the culture distance existed between the home and the host countries, the weaker the cross-national SBS effect could be observed.

Contradictory to the common sense, consumers in high uncertainty avoidance and collectivistic nations do not pay more attention to brand signals. This could be a result of a limited sample of countries in the analysis, but more likely it could be caused by the product category we investigated. Previous research found significant moderating effects for uncertainty avoidance and individualism mostly for fast-moving consumable and durable goods (Erdem et al., 2006). Movies are experiential products, the quality of which cannot be accurately assessed before consumption. The quality evaluation of such products is also more subjective than search products. The risks of consuming an undesirable movie product include the monetary cost of product purchase, the time cost for watching the movie, and perhaps more importantly, the discontent from not experiencing expected pleasure and fun. To avoid these risks, consumers from high uncertainty avoidance cultures might go beyond the SBS effects to search for more profound and diagnostic signals, such as expert reviews and comments (Akdeniz and Talay, 2013). After all, SBS effects are mostly volume-based, and they lack the depth for more confident judgement to be made upon. Therefore, the interaction effect of uncertainty avoidance was not significant in the results. Similarly, individualistic consumers are less influenced by social persuasions, but meanwhile become more confident of their own interpretation of brand signals, especially for consumptions related to personal tastes and individual gratifications (Frank et al., 2015). The SBS effects provide overall signals for consumers to observe. The diagnosticity of such signals may be 
increased among individualistic consumers, when the information is carefully elaborated and internalized. It should also be noted that our analysis did not take the correlations among cultural values into consideration. Simultaneous estimation of all cultural dimensions would offer more insights, if multicollinearity can be reduced through an investigation of more countries. Meanwhile, masculinity is not investigated in the paper, because directly hypothesizing how masculinity moderates the effect of marketing signals is not plausible.

Not only did culture moderate the SBS effects, it affected the intrinsic preference for auxiliary channels as well. Short-term-oriented and indulgent consumers buy more from auxiliary channels according to the results. While the main effects of these two dimensions need to be retested in a more stringent context, we still find theoretical consistency between the results and previous studies. Short-term-oriented and indulgent consumers have innate preference for hedonic products such as movies (Akdeniz and Talay, 2013). Auxiliary channels can provide hedonic consumption at any convenient time and in any desirable way to consumers, which might increase the level of hedonics, and therefore DVDs and online streaming services are preferred by short-term-oriented and indulgent consumers.

We found a strong positive correlation between unmeasured marketing characteristics of movies (e.g., word of mouth, advertising budgets, etc.) and the error term in Equation (5). This finding implied that the studio used unmeasured marketing characteristics to make decisions on sequential distributions of movies. Studios tended to increase the time window between theatrical and auxiliary channels for movies with positive marketing signals, such as better word of mouth and more advertising spending. Conversely, if unmeasured marketing characteristics were to decrease demand for DVDs, the time window would be shorter than it would have otherwise been. More research effort is required to gauge the actual role of time intervals in sequential distributions. 
Findings in the paper offer managerial suggestions to sequential distributions of experiential products. Although a limited number of nations involved in this study prevented a further generalization across nations, the results painted a picture of an international auxiliary channel diffusion process. When the market performance of theatrical releases was satisfactory in the host nations, marketers could first choose markets that were low in power distance and long-term orientation but high in indulgence to undertake cross-channel sequential distribution. For cross-national sequential releases of auxiliary channel products, managers should target nations with less cultural distance to the home country, and a prime example of such markets was to release US movie products in auxiliary channels of UK. Again, with data from only six nations, it would be difficult to generate accurate effect sizes of cultural influence, so we urge managers to use the findings in the paper as one of the available suggestions for international marketing. Although the sales estimates may not be accurate due to the exclusion of marketing variables such as advertising budgets and prices for the main channel, they will at least provide directional information for managerial decisions where the SBS effects are to be unleashed.

We tested the cultural relevance of the SBS effects using data from the DVD channel. It is arguable that a more prominent auxiliary channel has already emerged to replace the DVD market, which is the online movie-on-demand market, or online streaming services for movies. Revenues of top companies in this new auxiliary channel have been growing enthusiastically while the traditional DVD business has been shrinking in size. For example, Netflix, originally in the DVD business, recorded revenue of 11.7 billion USD in 2017 for online business, which was $32.4 \%$ more than the revenue of 2016 . An important question needs to be answered here: are the findings developed in the DVD channel in this paper generalizable to online channels? 
Theoretical generalization is only possible when the two auxiliary channels share similarity or the theoretical premises of the findings can be transplanted to a new auxiliary channel without adaptation. Therefore, we compare these two auxiliary channels first from aspects of time intervals, nature of products, and the decision making process of consumers. The time intervals between releases in the main and auxiliary channels have been shortened (Eliashberg et al., 2006). In 2005, DVDs took around 70 days on average to be published after theatrical releases of movies, and the delays between online and theatrical releases are reduced to a few weeks at the moment. Shortened intervals would result in stronger SBS effects due to the carryover effects of marketing communications and buzz from the theatrical releases (Ahmed and Sinha, 2016). Meanwhile, the basis of our theoretical argument for moderations of long-term orientation hinges on short intervals between sequential distributions and movie buzz from the main channel. Therefore, the moderation effect of long-term orientation is expected to be even stronger in the context of online streaming services.

The online streaming services are more readily accessible to consumers than DVDs, where shipment is required before consumption. Therefore, online auxiliary channel is featured by the possibility of immediate gratification after the exposure to the SBS effects. This change may accentuate the moderation effect of long-term orientation and indulgence, because when gratification or indulgence becomes temporally closer to the SBS effects, they can be more susceptible to such effects. Consumers in short-term-oriented and indulgent cultures would more frequently encounter scenarios of immediate gratification or indulgence, and the influence of the SBS effects would play a more important role in these scenarios. In terms of the decision making process, the information searching activity, which is related to the SBS effects, can be accomplished online now in the context of online auxiliary channels. Researchers argue that long-term-orientated consumers may resist online information 
searching because they are not early adopters of innovations (Donthu and Yoo, 1998). Consumers with high levels of indulgence are more open to online information searching and purchase (Lu et al., 2018). These arguments can be true when we investigate emerging markets where online streaming services are still considered as innovations. For developed markets such as the six nations in our sample, online movie watching is no longer categorized as an innovative behavior. It is also worth mentioning that DVDs can be bought in bulks but online streaming service is usually ordered for one product at a time. This may lead to differences in decision making, which may change the findings of the current study. Last but not least, cultural values are relatively stable. Hofstede argued that cultural scores should not have recognizable changes for a long period, perhaps until 2100 (Soares et al., 2007, Hofstede et al., 2010). This contributes to the generalizability of our findings. To sum up, although the two auxiliary channels are not completely the same, they share many similarities. The theoretical foundation of our argument can be applied to a new auxiliary channel or a new form of hedonic product without too much adaptation. We are relatively confident that the findings can be generalized.

\section{Limitations and future research directions}

We identified several limitations of this study and hoped that future research can tackle them. Although we modeled the effect of time intervals on DVD sales, the intervals were equally likely to influence box office revenues. Therefore, a comprehensive model that captures the effects of the time window on both the theatrical and DVD channels will provide more insight for choosing the length of the time window. We leave this topic for a future study. Similarly, our focus in this paper is to explore the interplay between channel types and cultural values. Cultural values can play multiple roles in the new product diffusion process. Future studies can explore the interaction of culture and genre, for example, to enhance the 
model's explanatory power. Moreover, according to the definition of culture, many other factors are equally, if not more, important than the cultural values in Hofstede's system. For example, language, rituals, customs, and religion are indispensable components of a culture. Other paradigms of cultural values also exist in academic research (e.g., Schwartz and Bilsky, 1990). Our study focuses on Hofstede's set of dimensions because it is the most tested and widely adopted system and offers measures across different nations. Future studies can include other cultural or non-cultural differences of nations to investigate the SBS effects in international markets. Also, we suggest that more countries to be included in the analysis of SBS effects to avoid the potential problem of multicollinearity due to the sampling of nations. Inclusion of more nations can enhance the generalizability of findings. Most importantly, the background of our research is the DVD channel. To fully generalize the findings to other auxiliary channels, empirical testing is required. 
Table 1 Studies on Sequential Distributions of Movies and Positioning of the Current Study

\begin{tabular}{|c|c|c|c|c|c|}
\hline Previous studies & $\begin{array}{c}\text { Main } \\
\text { channel }\end{array}$ & $\begin{array}{c}\text { Auxiliary } \\
\text { channel }\end{array}$ & $\begin{array}{c}\text { Dynamic } \\
\text { model }\end{array}$ & $\begin{array}{l}\text { Cross-national } \\
\text { study }\end{array}$ & $\begin{array}{l}\text { Effects o } \\
\text { culture }\end{array}$ \\
\hline Neelamegham and Chintagunta, 1999 & $\sqrt{ }$ & & $\sqrt{ }$ & $\sqrt{ }$ & \\
\hline Lehmann and Weinberg, 2000 & $\sqrt{ }$ & $\sqrt{ }$ & $\sqrt{ }$ & & \\
\hline Elberse and Eliashberg, 2003 & $\sqrt{ }$ & & $\sqrt{ }$ & $\sqrt{ }$ & \\
\hline Craig et al., 2005 & $\sqrt{ }$ & & & $\sqrt{ }$ & $\sqrt{ }$ \\
\hline Hennig-Thurau et al., 2006 & $\sqrt{ }$ & $\sqrt{ }$ & $\sqrt{ }$ & & \\
\hline Hui et al., 2008 & $\sqrt{ }$ & $\sqrt{ }$ & $\sqrt{ }$ & & \\
\hline Smith and Telang, 2009b & $\sqrt{ }$ & $\sqrt{ }$ & $\sqrt{ }$ & & \\
\hline Luan and Sudhir, 2010 & $\sqrt{ }$ & $\sqrt{ }$ & $\sqrt{ }$ & & \\
\hline Moon et al., 2010 & $\sqrt{ }$ & $\sqrt{ }$ & $\sqrt{ }$ & & \\
\hline Leenders and Eliashberg, 2011 & $\sqrt{ }$ & & & $\sqrt{ }$ & \\
\hline Broekhuizen et al., 2011 & $\sqrt{ }$ & & & $\sqrt{ }$ & \\
\hline Calzada and Valletti, 2012 & $\sqrt{ }$ & $\sqrt{ }$ & & & \\
\hline Akdeniz and Talay, 2013 & $\sqrt{ }$ & & & $\sqrt{ }$ & $\sqrt{ }$ \\
\hline Clement et al., 2014 & $\sqrt{ }$ & & & $\sqrt{ }$ & \\
\hline Ahmed and Sinha, 2016 & $\sqrt{ }$ & $\sqrt{ }$ & $\sqrt{ }$ & & \\
\hline Keuschnigg and Wimmer, 2017 & $\sqrt{ }$ & $\sqrt{ }$ & & & \\
\hline Dogruel, 2017 & $\sqrt{ }$ & & & $\sqrt{ }$ & \\
\hline Griffith et al., 2017 & $\sqrt{ }$ & & & $\sqrt{ }$ & \\
\hline Current study & $\sqrt{ }$ & $\sqrt{ }$ & $\sqrt{ }$ & $\sqrt{ }$ & $\sqrt{ }$ \\
\hline
\end{tabular}


Table 2 Summary of Variables

\begin{tabular}{|c|c|c|c|}
\hline Descriptions & Representation & Source & Reasons for inclusion \\
\hline DVD sales in host-countries & $D V D_{i j t}^{\text {host }}$ & IPSOS & Dependent variable \\
\hline Box office revenue in host-countries & Boxoffice $e_{i j t}^{\text {host }}$ & Box Office Mojo & Independent variable \\
\hline Box office revenue in the home-country & Boxoffice ${ }_{i j t}^{\text {home }}$ & Box Office Mojo & Independent variable \\
\hline Cultural value: individualism & $C V_{I D V j}$ & Hofstede et al. 2010 & Moderator \\
\hline Cultural value: power distance & $C V_{P D I j}$ & Hofstede et al. 2010 & Moderator \\
\hline Cultural value: uncertainty avoidance & $C V_{U A I j}$ & Hofstede et al. 2010 & Moderator \\
\hline Cultural value: long-term orientation & $C V_{L T O j}$ & Hofstede et al. 2010 & Moderator \\
\hline Cultural value: indulgence & $C V_{I D G j}$ & Hofstede et al. 2010 & Moderator \\
\hline Cultural distance & $C D_{j j^{\prime}}$ & Calculation & Moderator \\
\hline \multicolumn{4}{|c|}{ Control Variables } \\
\hline Whether a DVD is a special edition & Edition $_{i j}$ & IPSOS & Hennig-Thurau et al., 2006 \\
\hline Price of the product & Price $_{i j}$ & IPSOS & Luan and Sudhir, 2010 \\
\hline $\begin{array}{l}\text { Time intervals between host theatrical } \\
\text { and host DVD releases }\end{array}$ & Interval ${ }_{i j}^{\text {Movie }}$ & IPSOS & $\begin{array}{c}\text { Neelamegham and Chintagunta, } \\
1999\end{array}$ \\
\hline $\begin{array}{l}\text { Time lag between host DVD releases } \\
\text { and sales record }\end{array}$ & Interval $l_{i j}^{D V D}$ & IPSOS & Luan and Sudhir, 2010 \\
\hline Star power of a movie & Star $_{i}$ & IPSOS & Hofmann et al., 2017 \\
\hline $\begin{array}{l}\text { Whether a movie is a sequel from a } \\
\text { previous movie }\end{array}$ & Sequel $_{i}$ & IPSOS & Dhar et al., 2012 \\
\hline $\begin{array}{l}\text { Whether a DVD is a remake from } \\
\text { previous edition }\end{array}$ & Remake $_{i}$ & IPSOS & Bohnenkamp et al., 2015 \\
\hline User ratings of a movie & UserRating $_{i}$ & $\mathrm{IMDb}$ & Carrillat et al., 2018 \\
\hline Duration of a movie & Duration $_{i}$ & $\mathrm{IMDb}$ & Time cost \\
\hline Online streaming & Streaming $_{i}$ & Amazon and Vudu & Competing effect \\
\hline Piracy torrents & Torrents $_{i}$ & Search engines & Competing effect \\
\hline Piracy seeds & Seeds $_{i}$ & Search engines & Competing effect \\
\hline Piracy leeches & Leeches $_{i}$ & Search engines & Competing effect \\
\hline Content-based rating of a movie & Rating $_{i m}$ & MPAA & Leenders and Eliashberg, 2011 \\
\hline Genre of a movie & Genre $_{i l}$ & The Numbers & Keuschnigg and Wimmer, 2017 \\
\hline Penetration of DVD devices & Device $_{j}$ & Statista & Complement effect \\
\hline DVD distributors & Distributor $_{j}$ & IPSOS & Complement effect \\
\hline Studios that produce the movie & Studio $_{i s}$ & IPSOS & Luan and Sudhir, 2010 \\
\hline
\end{tabular}


Table 3 Country Specific Mean and Standard Deviation

\begin{tabular}{l|c|ccc|ccc}
\hline & Mumber & \multicolumn{3}{|c|}{ Means } & \multicolumn{3}{c}{ Standard Deviations } \\
Countries & $\begin{array}{c}\text { DVD } \\
\text { Ooles } \\
\text { Movies }\end{array}$ & $\begin{array}{c}\text { Time } \\
\text { Intervals } \\
\text { Units) }\end{array}$ & $\begin{array}{c}\text { Box Office } \\
\text { (Devenue } \\
\text { (Millions) }\end{array}$ & $\begin{array}{c}\text { Sales } \\
(1000 \\
\text { Units) }\end{array}$ & $\begin{array}{c}\text { Time } \\
\text { Intervals } \\
\text { (Days) }\end{array}$ & $\begin{array}{c}\text { Box Office } \\
\text { Revenue } \\
\text { (Millions) }\end{array}$ \\
\hline Germany & 57 & 66.58 & 73.97 & 10.99 & 115.26 & 76.60 & 13.38 \\
\hline Australia & 42 & 62.41 & 65.75 & 6.83 & 84.55 & 68.53 & 5.93 \\
\hline Japan & 34 & 139.52 & 67.93 & 22.89 & 192.36 & 70.05 & 27.28 \\
\hline UK & 75 & 330.37 & 76.10 & 12.99 & 501.60 & 87.93 & 19.66 \\
\hline USA & 104 & 375.16 & 66.43 & 74.61 & 407.67 & 72.43 & 80.08 \\
\hline France & 37 & 143.46 & 106.5 & 12.20 & 183.46 & 122.19 & 11.66 \\
\hline
\end{tabular}


Table 4 Correlations among Key Variables

\begin{tabular}{|c|c|c|c|c|c|c|c|c|c|c|c|c|c|c|c|c|c|c|c|c|c|c|}
\hline & 1 & 2 & 3 & 4 & 5 & 6 & 7 & 8 & 9 & 10 & 11 & 12 & 13 & 14 & 15 & 16 & 17 & 18 & 19 & 20 & 21 & 22 \\
\hline \multicolumn{23}{|l|}{ 1. DVD $D_{i j t}^{\text {host }}$} \\
\hline 2. Boxoffice ${ }_{i j t}^{\text {host }}$ & .626 & & & & & & & & & & & & & & & & & & & & & \\
\hline 3. Boxoffice home & .305 & .434 & & & & & & & & & & & & & & & & & & & & \\
\hline 4. $C V_{I D V j}$ & .284 & .241 & -.227 & & & & & & & & & & & & & & & & & & & \\
\hline 5. $C V_{U A I j}$ & -.229 & -.159 & .236 & -.372 & & & & & & & & & & & & & & & & & & \\
\hline 6. $C V_{P D I j}$ & -.080 & -.041 & .136 & -.665 & .557 & & & & & & & & & & & & & & & & & \\
\hline 8. $C V_{I D G j}$ & .263 & .215 & -.245 & .806 & -.738 & -.501 & -.729 & & & & & & & & & & & & & & & \\
\hline 9. $C D_{j j^{\prime}}$ & -.447 & -.587 & .199 & -.612 & .561 & .334 & .707 & -.702 & & & & & & & & & & & & & & \\
\hline 10. Edition $_{i j}$ & -.112 & .084 & .247 & -.091 & .090 & .056 & .088 & -.085 & .117 & & & & & & & & & & & & & \\
\hline 11. Price $_{i j}$ & .100 & .075 & .278 & -.040 & .001 & -.065 & .063 & -.053 & .055 & .001 & & & & & & & & & & & & \\
\hline 12. Interval ${ }_{i j}^{\text {Movie }}$ & -.026 & -.092 & .080 & -.071 & .161 & .288 & .113 & -.132 & .151 & .012 & -.080 & & & & & & & & & & & \\
\hline 13. Star $_{i}$ & .039 & .199 & .272 & -.100 & .068 & .026 & .103 & -.095 & .065 & .110 & -.056 & .053 & & & & & & & & & & \\
\hline 15. Remake $_{i}$ & .024 & .122 & .235 & -.132 & .144 & .088 & .109 & -.149 & .085 & .148 & -.075 & -.041 & .133 & .019 & & & & & & & & \\
\hline 16. UserRating ${ }_{i}$ & .126 & .207 & .223 & .023 & -.023 & -.027 & -.007 & -.014 & -.052 & .151 & .016 & -.003 & .395 & .228 & .097 & & & & & & & \\
\hline 17. Duration $i$ & .068 & .180 & .283 & -.097 & .083 & .031 & .085 & -.103 & .042 & .177 & .079 & -.047 & .370 & .034 & .319 & .453 & & & & & & \\
\hline 18. Streaming $i$ & .125 & .145 & .479 & -.162 & .171 & .109 & .150 & -.187 & .130 & .247 & .125 & -.036 & .164 & .539 & .312 & .423 & .305 & & & & & \\
\hline 19. Torrents $_{i}$ & .168 & .242 & .535 & -.184 & .207 & .146 & .156 & -.206 & .127 & .343 & -.009 & .072 & .240 & .368 & .289 & .564 & .498 & .737 & & & & \\
\hline 20. Seeds $s_{i}$ & .000 & -.021 & .017 & -.005 & .000 & .013 & -.005 & .021 & .003 & .026 & -.069 & -.108 & .008 & .086 & .062 & .176 & .040 & .168 & .281 & & & \\
\hline 21. Leeches ${ }_{i}$ & .072 & .102 & .227 & -.025 & .040 & .053 & .024 & -.029 & .029 & .139 & -.280 & -.068 & .203 & .121 & .275 & .327 & .155 & .327 & .394 & .726 & & \\
\hline 22. Device $_{j}$ & .411 & .514 & -.207 & .706 & -.625 & -.527 & -.731 & .617 & -.729 & -.118 & -.026 & -.179 & -.067 & -.025 & -.095 & .064 & -.046 & -.136 & -.146 & -.015 & -.038 & \\
\hline 23. Distributor ${ }_{j}$ & .436 & .484 & -.253 & .670 & -.674 & -.366 & -.555 & .618 & -.687 & -.127 & -.047 & -.079 & -.049 & -.029 & -.125 & .059 & -.058 & -.158 & -.172 & .003 & -.026 & .831 \\
\hline
\end{tabular}


Table 5 Estimation of Coefficients

\section{Dependent variable: DVD sales}

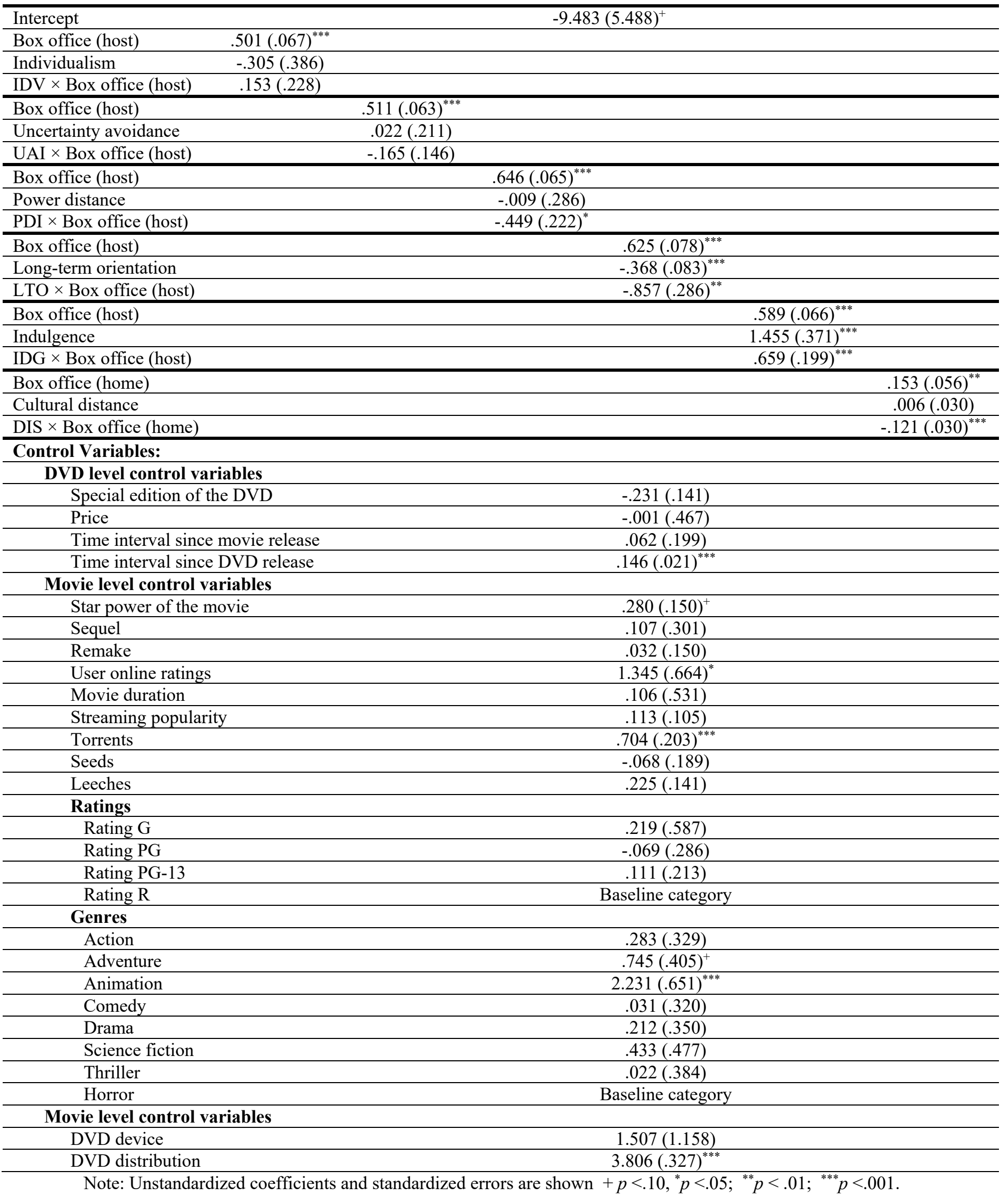


Figure 1 Effects of Markets and Channels on International DVD Sales

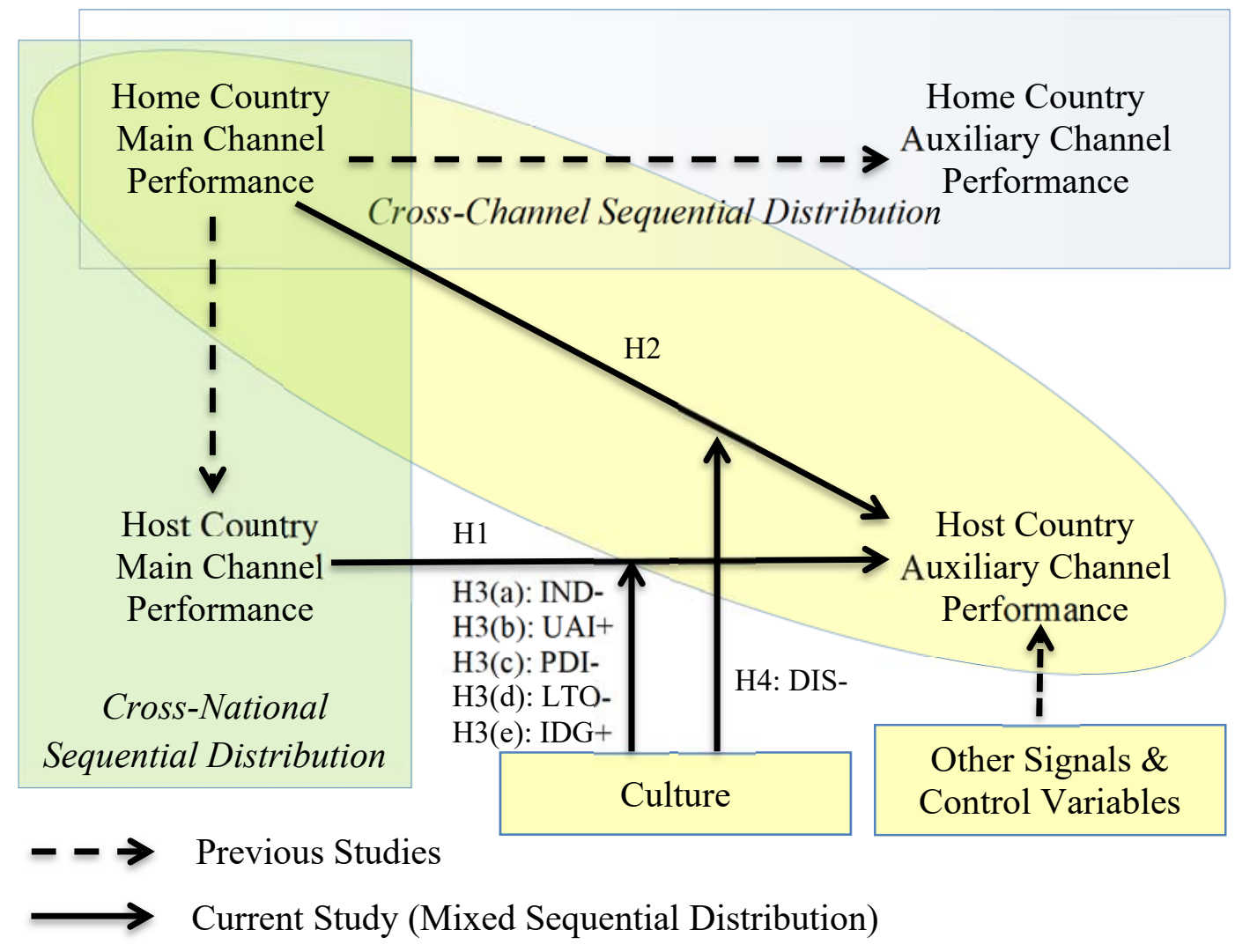

Note: $\quad \mathrm{IND}=$ individualism, $\mathrm{PDI}=$ power distance; $\mathrm{UAI}=$ uncertainty avoidance, LTO $=$ long-term orientation, IDG $=$ indulgence, DIS $=$ cultural distance. 
Figure 2: Scattered joint distribution of box office and DVD sales in six nations.

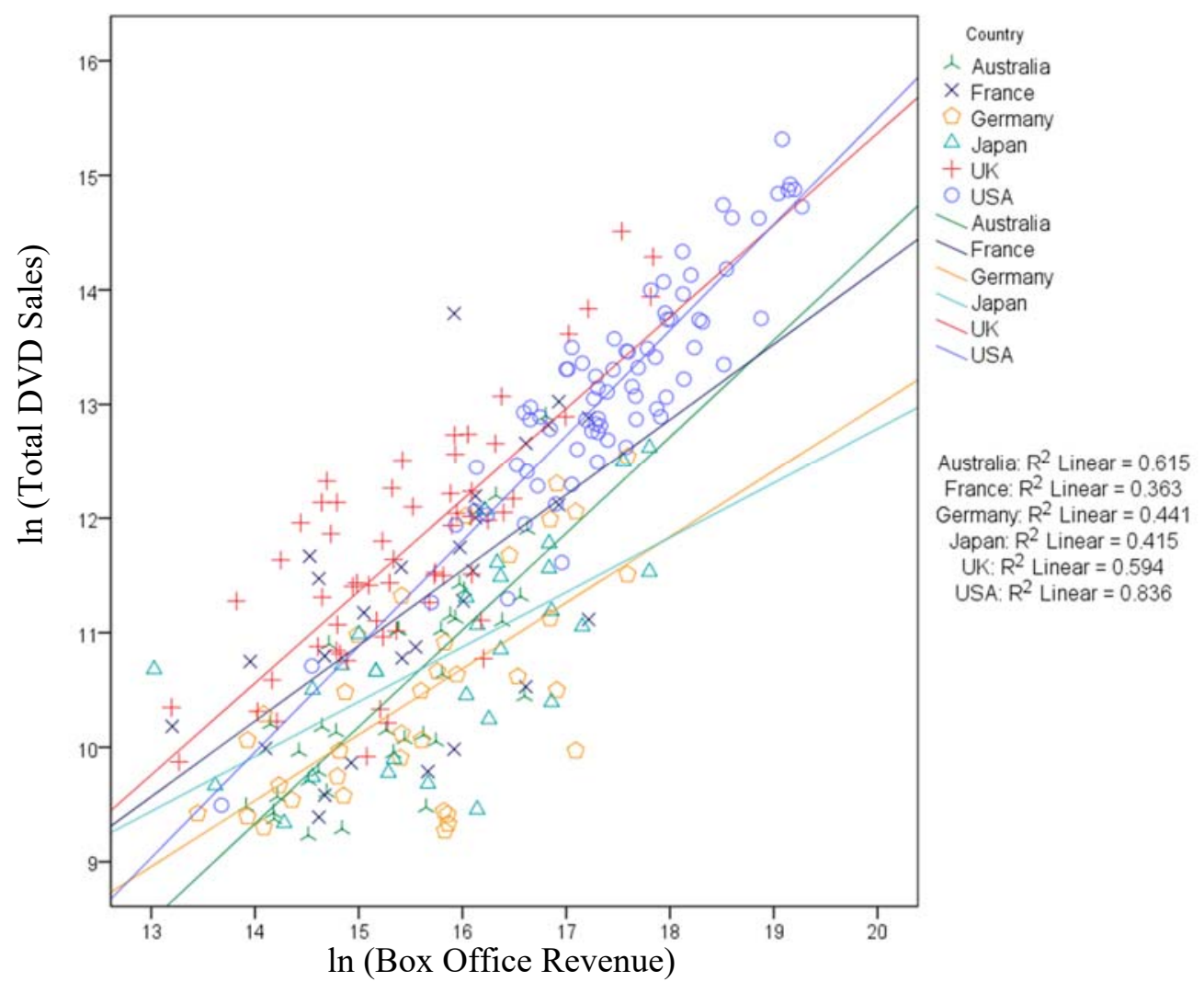


Figure 3: Scattered joint distribution of box office in US and DVD sales in five nations.

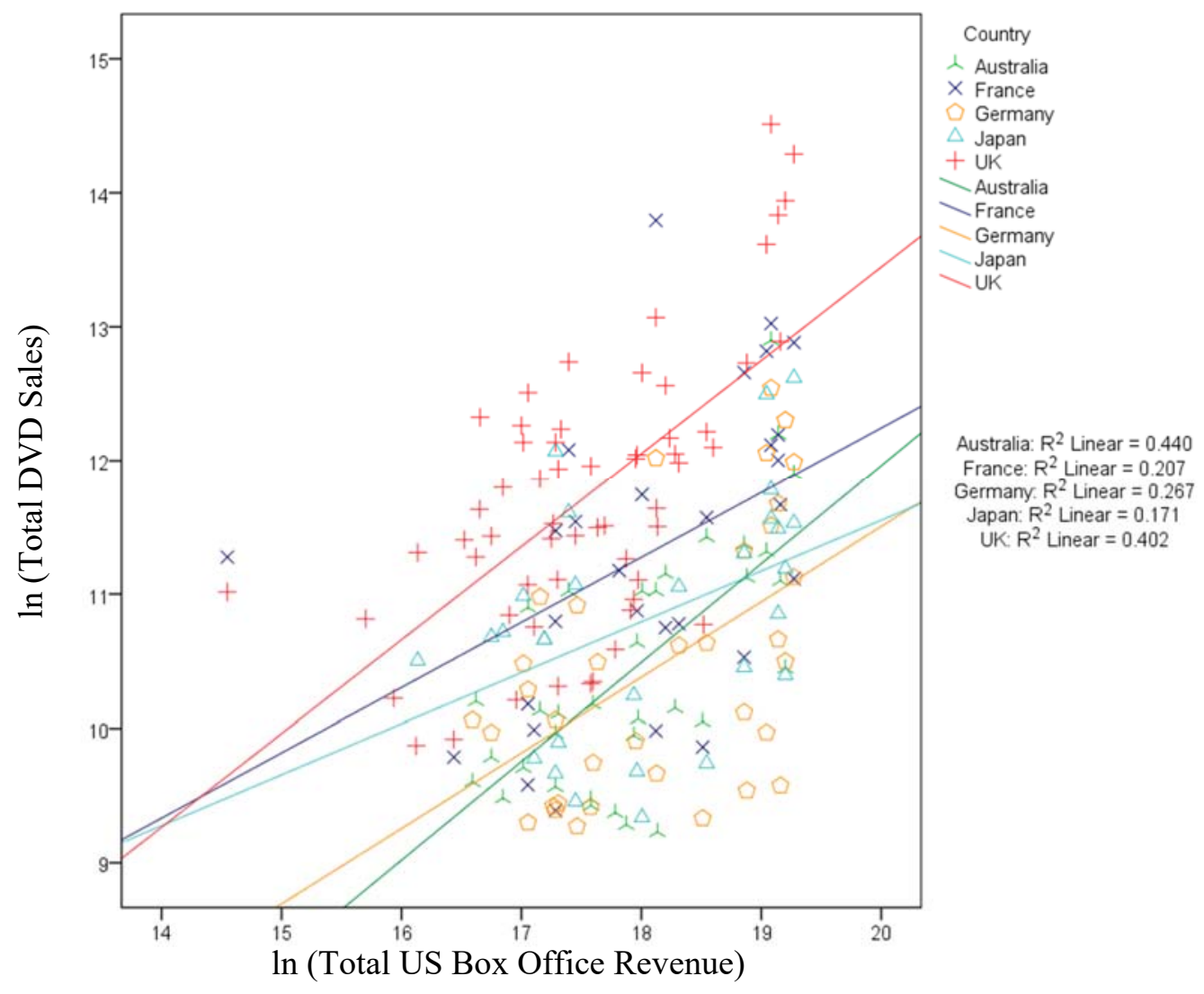




\section{References}

Ahmed, S. \& Sinha, A. 2016. When It Pays to Wait: Optimizing Release Timing Decisions for Secondary Channels in the Film Industry. Journal of Marketing, 80, 20-38.

Akdeniz, M. B. \& Talay, M. B. 2013. Cultural Variations in the Use of Marketing Signals: A Multilevel Analysis of the Motion Picture Industry. Journal of the Academy of Marketing Science, 41, 1-24.

Basuroy, S., Desai, K. K. \& Talukdar, D. 2006. An Empirical Investigation of Signaling in the Motion Picture Industry. Journal of Marketing Research, 287-295.

Bernerth, J. B. \& Aguinis, H. 2016. A Critical Review and Best-Practice Recommendations for Control Variable Usage. Personnel Psychology, 69, 229-283.

Bohnenkamp, B., Knapp, A.-K., Hennig-Thurau, T. \& Schauerte, R. 2015. When Does It Make Sense to Do It Again? An Empirical Investigation of Contingency Factors of Movie Remakes. Journal of Cultural Economics, 39, 15-41.

Bond, R. \& Smith, P. 1996. Culture and Conformity: A Meta-Analysis of Studies Using Asch's (1952b, 1956) Line Judgment Task. Psychological Bulletin, 119, 111-137.

Brewer, M. B. 2003. Optimal Distinctiveness, Social Identity, and the Self. In: LEARY, M. \& TANGNEY, J. (eds.) Handbook of Self and Identity.

Broekhuizen, T. L. J., Delre, S. A. \& Torres, A. 2011. Simulating the Cinema Market: How CrossCultural Differences in Social Influence Explain Box Office Distributions. Journal of Product Innovation Management, 28, 204-217.

Bruce, N. I., Foutz, N. Z. \& Kolsarici, C. 2012. Dynamic Effectiveness of Advertising and Word of Mouth in Sequential Distribution of New Products. Journal of Marketing Research, 49, 469486.

Calzada, J. \& Valletti, T. M. 2012. Intertemporal Movie Distribution: Versioning When Customers Can Buy Both Versions. Marketing Science, 31, 649-667.

Carrillat, F. A., Legoux, R. \& Hadida, A. L. 2018. Debates and Assumptions About Motion Picture Performance: A Meta-Analysis. Journal of the Academy of Marketing Science, 46, 273-299. 
Chan, C., Berger, J. \& Van Boven, L. 2012. Identifiable but Not Identical: Combining Social Identity and Uniqueness Motives in Choice. Journal of Consumer Research, 39, 561-573.

Childers, T. L. \& Rao, A. R. 1992. The Influence of Familial and Peer-Based Reference Groups on Consumer Decisions. Journal of Consumer Research, 19, 198-211.

Chintagunta, P. K., Gopinath, S. \& Venkataraman, S. 2010. The Effects of Online User Reviews on Movie Box Office Performance: Accounting for Sequential Rollout and Aggregation across Local Markets. Marketing Science, 29, 944-957.

Chung, J. 2011. Investigating the Roles of Online Buzz for New Product Diffusion and Its CrossCountry Dynamics. Journal of Business Research, 64, 1183-1189.

Clement, M., Wu, S. \& Fischer, M. 2014. Empirical Generalizations of Demand and Supply Dynamics for Movies. International Journal of Research in Marketing, 31, 207-223.

Craig, C. S., Greene, W. H. \& Douglas, S. P. 2005. Culture Matters: Consumer Acceptance of Us Films in Foreign Markets. Journal of International Marketing, 13, 80-103.

Dawar, N. \& Parker, P. 1994. Marketing Universals: Consumers' Use of Brand Name, Price, Physical Appearance, and Retailer Reputation as Signals of Product Quality. Journal of Marketing, 8195.

Dawar, N., Parker, P. M. \& Price, L. J. 1996. A Cross-Cultural Study of Interpersonal Information Exchange. Journal of International Business Studies, 27, 497-516.

De Vany, A. \& Walls, W. D. 1999. Uncertainty in the Movie Industry: Does Star Power Reduce the Terror of the Box Office? Journal of Cultural Economics, 23, 285-318.

De Vany, A. S. \& Walls, W. D. 2007. Estimating the Effects of Movie Piracy on Box-Office Revenue. Review of Industrial Organization, 30, 291-301.

Deutsch, M. \& Gerard, H. B. 1955. A Study of Normative and Informational Social Influences Upon Individual Judgment. Journal of Abnormal Psychology, 51, 629-36.

Dhar, T., Sun, G. \& Weinberg, C. B. 2012. The Long-Term Box Office Performance of Sequel Movies. Marketing Letters, 23, 13-29. 
Divakaran, P. K. P., Palmer, A., Søndergaard, H. A. \& Matkovskyy, R. 2017. Pre-Launch Prediction of Market Performance for Short Lifecycle Products Using Online Community Data. Journal of Interactive Marketing, 38, 12-28.

Dogruel, L. 2017. Cross-Cultural Differences in Movie Selection. Decision-Making of German, U.S., and Singaporean Media Users for Video-on-Demand Movies. Journal of International Consumer Marketing, 1-13.

Donthu, N. \& Yoo, B. 1998. Cultural Influences on Service Quality Expectations. Journal of Service Research, 1, 178-186.

Duan, W., Gu, B. \& Whinston, A. B. 2008. The Dynamics of Online Word-of-Mouth and Product Sales—an Empirical Investigation of the Movie Industry. Journal of Retailing, 84, 233-242.

Dwyer, S., Mesak, H. \& Hsu, M. 2005. An Exploratory Examination of the Influence of National Culture on Cross-National Product Diffusion. Journal of International Marketing, 13, 1-27.

Eisingerich, A. B. \& Rubera, G. 2010. Drivers of Brand Commitment: A Cross-National Investigation. Journal of International Marketing, 18, 64-79.

Elberse, A. \& Eliashberg, J. 2003. Demand and Supply Dynamics for Sequentially Released Products in International Markets: The Case of Motion Pictures. Marketing Science, 22, 329-354.

Eliashberg, J., Elberse, A. \& Leenders, M. A. 2006. The Motion Picture Industry: Critical Issues in Practice, Current Research, and New Research Directions. Marketing Science, 25, 638-661.

Erdem, T. \& Swait, J. 1998. Brand Equity as a Signaling Phenomenon. Journal of Consumer Psychology, 7, 131.

Erdem, T., Swait, J. \& Valenzuela, A. 2006. Brands as Signals: A Cross-Country Validation Study. Journal of Marketing, 70, 34-49.

Erdem, T., Zhao, Y. \& Valenzuela, A. 2004. Performance of Store Brands: A Cross-Country Analysis of Consumer Store-Brand Preferences, Perceptions, and Risk. Journal of Marketing Research, 41, 86-100.

Festinger, L. \& Carlsmith, J. M. 1959. Cognitive Consequences of Forced Compliance. Journal of Abnormal and Social Psychology, 58, 203-210. 
Frank, B., Enkawa, T. \& Schvaneveldt, S. J. 2015. The Role of Individualism Vs. Collectivism in the Formation of Repurchase Intent: A Cross-Industry Comparison of the Effects of Cultural and Personal Values. Journal of Economic Psychology, 51, 261-278.

Ganesh, J. \& Kumar, V. 1996. Capturing the Cross-National Learning Effect: An Analysis of an Industrial Technology Diffusion. Journal of the Academy of Marketing Science, 24, 328-337.

Ganesh, J., Kumar, V. \& Subramaniam, V. 1997. Learning Effect in Multinational Diffusion of Consumer Durables: An Exploratory Investigation. Journal of the Academy of Marketing Science, 25, 214-228.

George, C., Nina, M. \& Evmorfia, A. 2012. Cross-National Differences in E-Wom Influence. European Journal of Marketing, 46, 1689-1707.

Goodrich, K. \& De Mooij, M. 2014. How ‘Social’ Are Social Media? A Cross-Cultural Comparison of Online and Offline Purchase Decision Influences. Journal of Marketing Communications, 20, 103-116.

Griffith, D. A., Yalcinkaya, G., Rubera, G. \& Giannetti, V. 2017. Understanding the Importance of the Length of Global Product Rollout: An Examination in the Motion Picture Industry. Journal of International Marketing, 25, 50-69.

Hennig-Thurau, T., Henning, V., Sattler, H., Eggers, F. \& Houston, M. B. 2007. The Last Picture Show? Timing and Order of Movie Distribution Channels. Journal of Marketing, 71, 63-83.

Hennig-Thurau, T., Houston, M. B. \& Walsh, G. 2006. The Differing Roles of Success Drivers across Sequential Channels: An Application to the Motion Picture Industry. Journal of the Academy of Marketing Science, 34, 559-575.

Hennig-Thurau, T., Wiertz, C. \& Feldhaus, F. 2015. Does Twitter Matter? The Impact of Microblogging Word of Mouth on Consumers' Adoption of New Movies. Journal of the Academy of Marketing Science, 43, 375-394.

Hofmann, J., Clement, M., Völckner, F. \& Hennig-Thurau, T. 2017. Empirical Generalizations on the Impact of Stars on the Economic Success of Movies. International Journal of Research in Marketing, 34, 442-461. 
Hofstede, G. 1980. Culture's Consequences: International Differences in Work-Related Values, Beverly Hills, CA, Sage.

Hofstede, G., Hofstede, G. \& Minkov, M. 2010. Cultures and Organizations: Software of the Mind, New York, McGraw-Hill.

Hui, S. K., Eliashberg, J. \& George, E. I. 2008. Modeling Dvd Preorder and Sales: An Optimal Stopping Approach. Marketing Science, 27, 1097-1110.

Johnson, J. \& Tellis, G. J. 2008. Drivers of Success for Market Entry into China and India. Journal of Marketing, 72, 1-13.

Karniouchina, E. V. 2011. Impact of Star and Movie Buzz on Motion Picture Distribution and Box Office Revenue. International Journal of Research in Marketing, 28, 62-74.

Kelman, H. C. 1958. Compliance, Identification, and Internalization: Three Processes of Attitude Change. The Journal of Conflict Resolution, 2, 51-60.

Keuschnigg, M. \& Wimmer, T. 2017. Is Category Spanning Truly Disadvantageous? New Evidence from Primary and Secondary Movie Markets. Social Forces, 96, 449-479.

Kim, Y. \& Zhang, Y. 2011. Does Power-Distance Influence Consumers Preference for Luxury Status Brands? Advances in Consumer Research, 39, 511-512.

Kogut, B. \& Singh, H. 1988. The Effect of National Culture on the Choice of Entry Mode. Journal of International Business Studies, 411-432.

Ladhari, R., Pons, F., Bressolles, G. \& Zins, M. 2011. Culture and Personal Values: How They Influence Perceived Service Quality. Journal of Business Research, 64, 951-957.

Leenders, M. a. a. M. \& Eliashberg, J. 2011. The Antecedents and Consequences of Restrictive AgeBased Ratings in the Global Motion Picture Industry. International Journal of Research in Marketing, 28, 367-377.

Lehmann, D. R. \& Weinberg, C. B. 2000. Sales through Sequential Distribution Channels: An Application to Movies and Videos. Journal of Marketing, 64, 18-33.

Liu, Y. 2006. Word of Mouth for Movies: Its Dynamics and Impact on Box Office Revenue. Journal of Marketing, 70, 74-89. 
Lu, Q., Pattnaik, C., Xiao, J. \& Voola, R. 2018. Cross-National Variation in Consumers' Retail Channel Selection in a Multichannel Environment: Evidence from Asia-Pacific Countries. Journal of Business Research, 86, 321-332.

Luan, Y. J. \& Sudhir, K. 2010. Forecasting Marketing-Mix Responsiveness for New Products. Journal of Marketing Research, 47, 444-457.

Minkov, M. \& Hofstede, G. 2011. Is National Culture a Meaningful Concept?: Cultural Values Delineate Homogeneous National Clusters of in-Country Regions. Cross-Cultural Research, 46, 133-159.

Mitra, D. \& Golder, P. N. 2002. Whose Culture Matters? Near-Market Knowledge and Its Impact on Foreign Market Entry Timing. Journal of Marketing Research, 350-365.

Money, R. B., Gilly, M. C. \& Graham, J. L. 1998. Explorations of National Culture and Word-ofMouth Referral Behavior in the Purchase of Industrial Services in the United States and Japan. Journal of Marketing, 62, 76-87.

Moon, S., Bergey, P. K. \& Iacobucci, D. 2010. Dynamic Effects among Movie Ratings, Movie Revenues, and Viewer Satisfaction. Journal of Marketing, 74, 108-121.

Moscovici, S. 1980. Toward a Theory of Conversion Behavior. In: BERKOWITZ, L. (ed.) Advances in Experimental Social Psychology. Academic Press.

Mourali, M., Pons, F. \& Laroche, M. 2005. Individualistic Orientation and Consumer Susceptibility to Interpersonal Influence. Journal of Services Marketing, 19, 164-173.

Mpaa. 2011. Theatrical Market Statistics 2010 [Online]. Available:

http://www.mpaa.org/researchStatistics.asp [Accessed March 2012].

Mpaa 2017. Theatrical Market Statistics 2016.

Nail, P. 1986. Toward an Integration of Some Models and Theories of Social Response.

Nath, P., Devlin, J. \& Reid, V. 2018. The Effects of Online Reviews on Service Expectations: Do Cultural Value Orientations Matter? Journal of Business Research, 90, 123-133.

Neelamegham, R. \& Chintagunta, P. 1999. A Bayesian Model to Forecast New Product Performance in Domestic and International Markets. Marketing Science, 18, 115-136. 
Neelamegham, R. \& Jain, D. 1999. Consumer Choice Process for Experience Goods: An Econometric Model and Analysis. Journal of Marketing Research, 36, 373-386.

Ng, K. Y. \& Van Dyne, L. 2001. Individualism-Collectivism as a Boundary Condition for Effectiveness of Minority Influence in Decision Making. Organizational Behavior and Human Decision Processes, 84, 198-225.

Ogden, H. \& Cheng, S. 2011. Cultural Dimensions and Materialism: Comparing Canada and China. Asia Pacific Journal of Marketing and Logistics, 23, 431-447.

Park, S. \& Gupta, S. 2009. Simulated Maximum Likelihood Estimator for the Random Coefficient Logit Model Using Aggregate Data. Journal of Marketing Research, 46, 531-542.

Pornpitakpan, C. \& Francis, J. N. P. 2000. The Effect of Cultural Differences, Source Expertise, and Argument Strength on Persuasion. Journal of International Consumer Marketing, 13, 77-101. Putsis, J. W. P., Balasubramanian, S., Kaplan, E. H. \& Sen, S. K. 1997. Mixing Behavior in CrossCountry Diffusion. Marketing Science, 16, 354-369.

Raghunathan, R. \& Corfman, K. 2006. Is Happiness Shared Doubled and Sadness Shared Halved? Social Influence on Enjoyment of Hedonic Experiences. Journal of Marketing Research, 386394.

Roth, M. S. 1995. The Effects of Culture and Socioeconomics on the Performance of Global Brand Image Strategies. Journal of Marketing Research, 163-175.

Schwartz, S. H. \& Bilsky, W. 1990. Toward a Theory of the Universal Content and Structure of Values: Extensions and Cross-Cultural Replications. Journal of Personality and Social Psychology, 58, 878.

Shavitt, S., Lalwani, A. K., Zhang, J. \& Torelli, C. J. 2006. The Horizontal/Vertical Distinction in Cross-Cultural Consumer Research. Journal of Consumer Psychology, 16, 325-342.

Smith, M. D. \& Telang, R. 2009a. Competing with Free: The Impact of Movie Broadcasts on Dvd Sales and Internet Piracy. MIS Quarterly, 33, 321-338.

Smith, M. D. \& Telang, R. 2009b. Competing with Free: The Impact of Movie Broadcasts on Dvd Sales and Internet Piracy 1. MIS Quarterly, 33, 321-338. 
Soares, A. M., Farhangmehr, M. \& Shoham, A. 2007. Hofstede's Dimensions of Culture in International Marketing Studies. Journal of Business Research, 60, 277-284.

Steenkamp, J.-B. E. M., Hofstede, F. T. \& Wedel, M. 1999. A Cross-National Investigation into the Individual and National Cultural Antecedents of Consumer Innovativeness. Journal of Marketing, 63, 55-69.

Tellis, G. J., Stremersch, S. \& Yin, E. 2003. The International Takeoff of New Products: The Role of Economics, Culture, and Country Innovativeness. Marketing Science, 22, 188-208.

The Convergence Consulting Group 2016. The Battle for the North American (Us/Canada) Couch Potato: Online \& Traditional Tv and Movie Distribution.

Tifferet, S. \& Herstein, R. 2010. The Effect of Individualism on Private Brand Perception: A CrossCultural Investigation. Journal of Consumer Marketing, 27, 313-322.

Van Everdingen, Y. M. \& Waarts, E. 2003. The Effect of National Culture on the Adoption of Innovations. Marketing Letters, 14, 217-232.

Wan, W. W. N., Luk, C.-L., Fam, K.-S., Wu, P. \& Chow, C. W. C. 2012. Interpersonal Relationship, Service Quality, Seller Expertise: How Important Are They to Adolescent Consumers? Psychology \& Marketing, 29, 365-377.

Wang, X., Wang, X., Fang, X. \& Jiang, Q. 2018. Power Distance Belief and Brand Personality Evaluations. Journal of Business Research, 84, 89-99.

Weinberg, C. B. 2005. Profits out of the Picture: Research Issues and Revenue Sources Beyond the North American Box Office. In: MOUL, C. C. (ed.) A Concise Handbook of Movie Industry Economics. New York: Cambridge University Press.

Weinberg, C. B. 2006. Research and the Motion Picture Industry. Marketing Science, 25, 667-669.

Weinberg, C. B. \& Moul, C. 2005. Profits out of the Picture: Research Issues and Revenue Sources Beyond the North American Box Office. A concise handbook of movie industry economics, $56,129-133$.

Xu, J. \& Schwarz, N. 2009. Do We Really Need a Reason to Indulge? Journal of Marketing Research, 46, 25-36. 
Yaveroglu, I. S. \& Donthu, N. 2002. Cultural Influences on the Diffusion of New Products. Journal of International Consumer Marketing, 14, 49-63. 